ARTIGOS

\title{
COMPROMETIMENTO ADMINISTRATIVO NA ADVANCE COMUNICAÇÃO: UM ESTUDO DA PERCEPÇÃO DOS GESTORES
}

\section{RESUMO}

Este artigo apresenta um estudo sobre o comprometimento administrativo na Advance Comunicação à luz da percepção dos gestores. O objetivo deste estudo é verificar o grau de comprometimento dos gestores da Advance Comunicação e o quanto estes se identificam com a empresa. Na pesquisa realizada, questiona-se como se estabelece a relação entre o comprometimento dos gestores da Advance com a satisfação no trabalho, a qualidade de vida no trabalho e quais os reflexos no desempenho. Para concretização da pesquisa, realizou-se um estudo com abordagem quantitativa. Foi utilizado para coleta de dados uma escala (NAVARRO et al., 2008), cuja análise ocorreu em função das categorias: comprometimento, identificação com a empresa, satisfação e desempenho. Como resultado, verificou-se que há um alto nível de afinidade entre os gestores e a empresa o que revela a base afetiva do comprometimento forte nessa instituição. Além disso, os gestores atestam que quanto mais satisfeito é o trabalhador, maior é seu desempenho. Considera-se, pois, que a organização pesquisada, de um modo geral, é gerenciada por pessoas comprometidas e satisfeitas com o que fazem. Também, é possível considerar que a instituição tem investido em gestão de pessoas, caso contrário não haveria satisfação por parte dos funcionários.

Palavras-chave: Comprometimento. Satisfação no Trabalho. Gestão de Pessoas.

jocilene_2@hotmail.com

Especialista em Práticas

Pedagógicas pelo Centro

Universitário Christus

(UNICHRISTUS) e concludente do MBA em Administração

Estratégica pela mesma instituição.

José Wilton Bessa Macedo Sá wilton.bessa@hotmail.com Mestre em Administração pela Universidade Estadual do Ceará (UECE). Docente no Centro Universitário Christus (UNICHRISTUS).

\section{INTRODUÇÃO}

Nas últimas décadas, o ambiente de trabalho vem sendo constantemente modificado pelas mudanças econômicas e exigências dos clientes, políticas e sociais. Desse modo, para se obter vantagens competitivas sobre esses impactos, as organizações precisam de colaboradores comprometidos para buscar estratégias que se adéquem às mudanças. Parte-se do pressuposto que o comprometimento sozinho não garante o sucesso da instituição, mas em determinado grau contribui de modo significativo para o alcance dos objetivos da empresa. Este estudo foca o comprometimento 
administrativo dos gestores da Advance Comunicação. A empresa hoje é a maior do Norte/Nordeste no segmento de publicidade e atua há mais de 20 anos no setor publicitário, trabalhando o pensamento estratégico aliado a ideias criativas e eficazes, objetivando sempre a satisfação e a solidificação de seus clientes no mercado.

Esta organização foi escolhida por sua relevância social e por ser formadora de opinião no setor de publicidade e propaganda e também por ter entre seus gestores talentos que já estão na casa há mais de 15 anos. Outro fator diz respeito ao acesso que a pesquisadora tem aos gestores e abertura que a empresa mantém na contribuição acadêmica.

$\mathrm{O}$ interesse da pesquisadora pelo tema comprometimento ocorre, porque é a partir dele que surgem comportamentos e ações que aumentam o desempenho do indivíduo. De acordo com Teixeira (1994, p. 268), “o estudo do comprometimento possibilita a melhor compreensão da natureza dos processos psicológicos pelos quais as pessoas escolhem identificar-se com os objetivos em seu ambiente [...]."

Assim, comprometimento organizacional, segundo Wiener (1982) compreende a internalização de pressões para ações que vão ao encontro de objetivos e metas organizacionais, levando empregados a pautar seu modo de agir em consonância com as crenças sobre o que consideram correto e moralmente aceitável, pode-se inferir que, estar comprometido com metas é fundamental para as organizações que pretendem se manter vivas no contexto atual, pois o comprometimento pode estar diretamente ligado ao desempenho no trabalho. As pessoas constituem o principal ativo da organização. Daí, a necessidade de tornar as organizações mais conscientes e atentas a seus funcionários.

Dessa forma, destacam-se como as questões da pesquisa: como se estabelece a relação entre o comprometimento dos gestores da $\mathrm{Ad}$ vance Comunicação com a satisfação no trabalho e quais os reflexos no desempenho?

A partir das questões, objetiva-se, em geral, analisar a relação entre o comprometimento dos gestores da Advance e a satisfação, bem como verificar a identificação destes com a empresa.

Quanto aos objetivos específicos, pretende-se:

a) compreender à luz da bibliografia o que é comprometimento organizacional;

b) verificar o grau de comprometimento dos gestores da Advance;

c) Reconhecer quanto os gestores se identificam com a empresa.

Ademais, o artigo contempla, além desta introdução, os tópicos que versam sobre a metodologia, a base teórica que sustenta a pesquisa, os resultados com as respectivas discussões e as considerações finais.

\section{METODOLOGIA}

O estudo se debruça sobre a percepção dos próprios gestores acerca do tema, uma vez que estes são os sujeitos da pesquisa de campo. Foi realizada uma pesquisa bibliográfica e de campo, exploratória, de cunho quantitativo, com delineamento descritivo, mediante estudo de caso. O recorte temporal da pesquisa aborda a última gestão da instituição. Portanto, os sujeitos da pesquisa correspondem a 14 gestores dos seguintes departamentos: RH, TI, diretoria financeira, diretoria de atendimento, diretoria de criação, diretoria de mídia, diretoria adjunta, gerência de Web, gerência de mídia, gerência de estúdio, gerência de produção, gerência financeira, gerência administrativa, gerência de contabilidade.

Para a composição bibliográfica, optou-se por autores como Bastos (2000); Tamayo (2005); Siqueira e Gomide Junior (2004); Morin (2001), entre outros.

Nessa pesquisa, realizou-se um estudo de caso com tratamento estatístico, pois traz um conjunto de dados quantitativamente coletados e relacionados. O estudo de caso é necessário porque "investiga um fenômeno contemporâneo dentro de seu contexto da vida real, especialmente quando os limites entre o fenômeno e o contexto não estão claramente definidos." (YIN, 2001, p. 32). 
Diante dessa descrição, é possível inferir que se lida com pesquisa quantitativa, uma vez que se utiliza de linguagem matemática para descrever as causas de um fenômeno e as relações entre variáveis [...] (MINAYO; SANCHES, 1993 apud TEIXEIRA, 2001).

Para a coleta de dados, foi aplicada uma escala proposta por Quijano (NAVARRO et al., 2008) aos gestores da Advance. Os instrumentais utilizados neste estudo foram desenvolvidos e validados pelo professor Santiago Díaz de Quijano (NAVARRO et al., 2008) e se destinam à avaliação de desempenho e satisfação de profissionais. O professore laborou o instrumental durante o desenvolvimento do projeto Estudo de clima organizacional (2006), coordenado por ele, na Universidade de Barcelona.

A aplicação da escala é necessária quando se pretende medir aspectos como atitudes ou opiniões do público-alvo, como é ocaso desse estudo. As pesquisas nessa área apontam para quatro tipos de escala: escala de Likert, VAS (Visual AnalogueScales), escala Numérica e escala Guttman. Para esta pesquisa a escala de Likert é a mais apropriada:

A escala de Likert apresenta uma série de cinco proposições, das quais o inquirido deve selecionar uma, podendo ser: concorda totalmente, concorda, sem opinião, discorda, discorda totalmente. É efetuada uma cotação das respostas que varia de modo consecutivo: $+2,+1,0,-1,-2$ ou utilizando pontuações de 1 a 5 . É necessário ter atenção quando a proposição é negativa. Nestes casos a pontuação atribuída deverá ser invertida (AMARO; POVOA; MACEDO, 2005, p. 5).

Após a aplicação da escala, foi feita a análise mediante categorização dos resultados. As categorias são: comprometimento, identificação com a empresa, satisfação e desempenho. Os resultados estão dispostos em gráficos para facilitar sua visualização complementada de fundamentação teórica.
A resolução 466/12 preconiza que o respeito, devido à dignidade humana, exige que toda pesquisa se processe após consentimento livre e esclarecido dos participantes, indivíduos ou grupos que por si e/ou por seus representantes legais manifestem a sua anuência à participação na pesquisa (BRASIL, 2012).

Dessa forma, foi agendada uma reunião com os gestores da organização, em que os instrumentais foram explicados para cada um dos gestores. Pôde-se contar com a pronta colaboração de todos os participantes, o que mostrou satisfatório nível de adesão, tornando essa etapa produtiva. No momento inicial, fez-se uma dinâmica para quebrar o gelo e em seguida explicitar o objetivo do projeto e como o resultado poderia trazer melhorias tanto para a organização como para melhor qualidade do trabalho.

Este trabalho é desenvolvido em sete capítulos que apresentam os seguintes temas: o capítulo 1 é a introdução, em que será explanado o cenário em que se encontra e o que se pretende observar, no capítulo 2 , sobre a metodologia adotada: detalha os procedimentos e os passos percorridos durante o estudo de caso. Os capítulos 3 e 4 são os embasamentos teóricos, nos quais explanarão, as organizações e o comprometimento humano no trabalho e o comprometimento organizacional, já o capítulo 5 serão abordados os resultados do trabalho realizado na empresa e, no capítulo 6, escreve-se sobre as considerações finais do trabalho.

\section{AS ORGANIZAÇÕES E O COM- PORTAMENTO HUMANO NO TRABALHO}

Este tópico apresenta o conceito de organização, as principais vertentes conceituais do comportamento humano no trabalho com destaque para os principais modelos e teorias sobre esse tema. As evidências da relação entre comprometimento e desempenho empresarial constarão no último tópico deste estudo. 


\subsection{CONCEITUANDO ORGANIZAÇÃO}

Antes de adentrar no assunto comprometimento organizacional, é importante salientar de qual organização pretende-se falar, além de seu conceito.

As organizações que tratam o presente estudo são, segundo Reichers (1985), constituídas de múltiplos segmentos que nem sempre partilham os mesmos objetivos e valores. Por exemplo: os gerentes, os trabalhadores, os consumidores ou clientes e os sindicatos. "A organização, para muitos empregados, é uma abstração - uma abstração representada, na realidade, por colegas de trabalho, superiores, subordinados, clientes e outros grupos e indivíduos que coletivamente integram uma organização." (REICHERS, 1985, p. 472).

Há quem simplifique o conceito afirmando ser "apenas a organização dos fatores de produção posta a funcionar pelo empresário." (HENTZ, 1998, p. 57). No entanto, Tamayo (2005) preconiza que as organizações são o lugar privilegiado em que se desenvolvem a identidade profissional do trabalhador e o ambiente social em que a pessoa se realiza do ponto de vista pessoal, social e profissional.

Nessa perspectiva, pode-se identificar uma compreensão mais clara acerca das implicações que o trabalho, reconhecido aqui pela categoria emprego e as organizações como portadoras de determinadas características que podem implicar positivamente nos comportamentos, percepções e relacionamentos que as pessoas mantêm com ela.

Ratificando esta visão de Tamayo (2005) de forma mais ampla, pode-se compreender organização, então, como o grupo que atua em determinado contexto realizando tarefas coordenadas, visando atingir alguns objetivos, geralmente dirigidos por alguém que exerce a função de planejar e organizar a execução das tarefas. De acordo com Bastos:

Esse pressuposto traz claras implicações para o estudo do comprometimento organizacional que deveria, a exemplo do que ocorre com os conceitos de satisfação no trabalho e de clima organizacional, ir além de uma medida global, decomposta em comprometimentos específicos. Tal reconceptualização abre a possibilidade de se estudar conflito entre comprometimentos (BASTOS, 1997, p. 99, grifo do autor).

Cabe, além do exposto, abordar um dos destaques dessa citação: satisfação no trabalho, pois se trata de fator determinante no comprometimento do indivíduo com a empresa.

\subsection{GESTÃO DE PESSOAS E O COM- PORTAMENTO NO TRABALHO}

Em cenário de mudanças, a organização precisa estar alinhada em torno de definições estratégicas claras, sustentadas por uma gestão com amplo envolvimento e participação. É preciso, portanto, estabelecer um compromisso com a força de trabalho, baseado em respeito mútuo em uma comunicação aberta.

O momento atual exige ampla transformação, uma nova "filosofia de gestão", o que implica uma grande mudança no paradigma anterior. Por isso, atualmente as empresas têm alterado suas práticas gerenciais: em vez de investir diretamente nos clientes, investem nas pessoas que os atendem, buscam estreitar os laços entre todos os níveis de relacionamento, tanto interno como externo, dando origem à chamada gestão de pessoas. Trata-se do conjunto de políticas e práticas definidas de uma organização para orientar o comportamento humano e as relações interpessoais no ambiente de trabalho (FLEURY; FLEURY, 2001).

De acordo com Saad (2005), a gestão de pessoas é algo com que a empresa deve se preocupar. O fato de toda a organização estar baseada em pessoas mostra o quanto é importante a área de recursos humanos. São as pessoas que definem metas de vendas, planejam e vendem produtos, assim, a forma de administrar dessas pessoas influencia de total maneira no desempenho geral da organização. O grande desafio 
das empresas de hoje é administrar bem seus recursos humanos, pois são as pessoas que obtêm e mantêm vantagens competitivas. É preciso saber como selecionar e desenvolver líderes, como atender melhor os clientes, como recompensar o bom desempenho, como controlar os custos de mão de obra e ao mesmo tempo manter um tratamento justo aos empregados.

Saad (2005) afirma ainda que deva ser feito um bom diagnóstico sobre a gestão de pessoas na organização. Um levantamento das condições organizacionais que são enfrentadas; planejar os objetivos na área de gestão de pessoas juntamente com os objetivos da organização; avaliar os resultados constantemente.

\subsection{SATISFAÇÃO NO TRABALHO}

Ao contrário do que alguns pensam, satisfação no trabalho não se limita somente à garantia dos direitos legais, estabilidade ou especialização no que se faz. Muitos estudos apontam que esse sentimento pode ser traduzido a partir de múltiplos fatores como crescimento profissional, qualidade de vida, ambiente propício para o desenvolvimento de pessoas e reconhecimento, entre outras características, num misto de fatores intrínsecos e extrínsecos.

Manter-se satisfeito diante das crises, turbulências e pressões que acometem o mundo do trabalho atualmente não é uma tarefa fácil, mas deve ser uma responsabilidade compartilhada entre as organizações e seus empregados. Mas, afinal, como definir o sentimento de satisfação no trabalho? Locke o define como "[...] um estado emocional positivo ou de prazer, resultante de um trabalho ou de experiências de trabalho." (LOCKE, 1976 apud SIQUEIRA; GOMIDE JUNIOR, 2004, p. 302).

Fatores como oportunidade de desenvolvimento, bom clima organizacional, ${ }^{1}$ com processos transparentes são formas de estimular a satisfação no trabalho. "Trabalhador satisfeito com seu trabalho pode se tornar uma pessoa com mais possibilidades de ser um cidadão integrado à sociedade, a sua família e apresentar melhores índices de bem-estar físico e mental." (LOCKE,
1976 apud SIQUEIRA; GOMIDE JUNIOR, 2004, p. 302). Além disso, pode aumentar o nível de comprometimento com a empresa.

Nesse sentido, Siqueira e Gomide Júnior (2004) confirmam que além do vínculo contratual formal, outros relacionamentos se estabelecem entre indivíduos e o trabalho e, especificamente, entre estes e as organizações. Desse conjunto de relações criam-se elementos específicos para a emergência da subjetividade mediante as percepções e comportamentos que se apresentam como desafios inerentes às relações interpessoais e intergrupais.

Nesse cenário, podem-se destacar alguns fatores como fonte de satisfação no trabalho: chefia, colegas de trabalho, o próprio trabalho, salário e oportunidades de promoção. Como grande parte das pessoas não escolhe seus empregos aleatoriamente e tende a buscar posições que sejam compatíveis com seus interesses, valores e habilidades, a satisfação é um termo que reflete no comprometimento de um profissional em relação ao trabalho que realiza.

\subsection{ENVOLVIMENTO COM O TRABA- LHO}

O envolvimento no trabalho mede o grau em que uma pessoa se identifica psicologicamente com o seu trabalho, considerando-se o seu nível de desempenho importante para sua própria valorização. Refere-se aos laços criados entre o indivíduo e o seu fazer; reflete o significado que o trabalho tem na vida da pessoa.

A psicologia, juntamente com a filosofia, demonstra as atitudes internas e perspectivas de vida de cada pessoa em seu trabalho e a importância do significado intrínseco das necessidades individuais para seu envolvimento com o exercício (VASCONCELOS, 2001). "Numa abordagem organizacional, envolvimento com o trabalho é considerado uma peça-chave para ativar a motivação dos trabalhadores e uma base fundamental para estabelecer vantagem competitiva nos negócios." (BROWN, 1996 apud SIQUEIRA; GOMIDE JUNIOR, 2004, p. 306).

Os trabalhadores com um nível elevado 
de envolvimento no trabalho se identificam fortemente com o que fazem e se interessam pelo tipo de trabalho que realizam. Morin (2001) destaca que para estimular o envolvimento com o trabalho, este deve apresentar algumas propriedades: 1) variedade e desafio; 2) aprendizagem contínua; 3) autonomia; 4) reconhecimento e apoio; 5) contribuição social; 6) futuro desejável. Esse modelo visa organizar o trabalho de tal forma que o comprometimento dos indivíduos seja estimulado e o desempenho melhorado.

Falar um pouco do comportamento no trabalho foi o objetivo desse tópico. $\mathrm{Na}$ etapa seguinte, são abordados os conceitos relativos a comprometimento em si.

\section{COMPROMETIMENTO ORGA- NIZACIONAL: EXPLICITANDO CONCEITOS}

O fenômeno do comprometimento no trabalho tem sido tratado como ponto central para a compreensão do comportamento nas organizações, pois está associado ao estabelecimento de relações interpessoais adequadas e à eficiência e eficácia individuais e organizacionais (BASTOS, 2000). Dessa forma, apesar de não ser fácil conceituar comprometimento, alguns autores se destacam nessas pesquisas Meyer e Allen (1997), Bastos (1993) e Becker (1992). Bastos foi pioneiro, no Brasil, em estudos dessa área.

\subsection{BASES DO COMPROMETIMENTO}

$\mathrm{Na}$ busca de conceituação, várias contribuições surgiram na tentativa de propor uma diferenciação entre os tipos de comportamento. Nessa direção O'Reilly e Chatman (1986 apud BASTOS, 1997, p. 7) destacam o apego psicológico como núcleo central desse construto.

Os autores discriminam três bases ou processos geradores de comprometimento organizacional: (a) complacência (submissão) ou troca, quando atitudes e comportamentos ocorrem em função de recompensas específicas e não por partilhar crenças, processo que pode levar a diferenças entre atitudes públicas e privadas; (b) identificação ou afiliação: o indivíduo aceita a influência para manter relação satisfatória pelo desejo de afiliação - sentir-se orgulhoso por pertencer, respeitar os valores, mas, não necessariamente, assumi-los como seus; (c) internalização, envolvimento que se apóia na identidade entre valores e objetivos pessoais e organizacionais (O'REILLY; CHATMAN 1986 apud BASTOS, 1997, p. 7, grifo do autor).

É comum identificar a ocorrência dessas bases em empresas, sobretudo, a internalização, no caso dos gestores quando estão altamente envolvidos com os objetivos da empresa, o que acontece na maioria das vezes, embora nem sempre seja uma opção.

Entre os diversos modelos de conceituação do comprometimento, Meyer e Allen (1997) possuem o modelo de maior aceitação entre os pesquisadores. Os autores também se apoiam na estrutura de três componentes: afetivo, de continuação e normativo, conforme se observa a seguir:

a) comprometimento afetivo: comprometimento como apego, envolvimento, onde ocorre identificação com a organização. "Empregados com um forte comprometimento afetivo permanecem na organização porque eles querem." (ALLEN; MEYER, 1991 apud MEDEIROS, 2003, p. 8);

b) comprometimento de continuação: nesse caso, empregados permanecem na empresa porque precisam;

c) comprometimento normativo: aqui os empregados pensam que são obrigados a continuar na empresa. (ALLEN; MEYER, 1991 apud MEDEIROS, 2003).

Assevera Bastos e Andrade (1992) que o comprometimento afetivo resulta de um vínculo em relação à organização. É representativo da 
identificação e do envolvimento do sujeito com ela. Meyer e Allen (1997) têm a mesma visão e acrescentam que esse vínculo tem implicação na resolução do indivíduo em permanecer na empresa. Siqueira e Gomide Junior (2004) demonstram que o vínculo afetivo com a organização tende a se tornar mais fortalecido à medida que os empregados percebem que a empresa está comprometida com eles. Reforça, ainda,

Quando o indivíduo internaliza os valores da organização, identifica-se com seus objetivos, se envolve com os papeis de trabalho, desempenhando-os de forma a facilitar a consecução dos objetivos do sistema, e deseja permanecer trabalhando para ela, considera-se que foi desenvolvida uma ligação psicológica, de natureza afetiva, com a organização (SIQUEIRA; GOMIDE JUNIOR, 2004, p. 316).

No caso do comprometimento de continuação, quando o indivíduo se sente preso ao lugar diante dos altos custos ligados ao fato de abandoná-lo, Becker (1960 apud BASTOS, 1997) descreve que o indivíduo permanece na organização analisando custos versus benefícios associados a sua saída (trocas laterais), ou seja, o empregado irá continuar na organização enquanto perceber benefícios nesta escolha. No momento em que perceber mais vantagens na saída, ele provavelmente deixará a organização. Mathieu e Zajac (1990 apud SIQUEIRA; GOMIDE JUNIOR, 2004, p. 318) acrescentam,

Esse tipo de comprometimento seria suscitado pela avaliação positiva de resultados [...] consequentes aos investimentos do empregado e, concomitantemente, pela possibilidade percebida de perder, ou de não ter como repor, vantagens decorrentes dos investimentos, caso se desligasse da organização.

$\mathrm{Na}$ abordagem normativa, o comprometimento é visto como a totalidade das pressões normativas internalizadas para que o empre- gado se comporte de acordo com os objetivos, as metas e os interesses da organização. Há o pressuposto de que o comportamento do empregado é conduzido de acordo com o conjunto de normas que ele assume internamente.

Essa abordagem difere da anterior porque leva o sujeito a pensar que é responsável, ou que tem obrigações para com a instituição em que trabalha, de modo que ele vai-se sentir ligado ao emprego, ou seja, considera que possui um "compromisso normativo", revestindo-se em sacrifício, persistência e preocupação pessoal (BASTOS, 1994).

Comentadas as bases do comprometimento, cabe, finalmente, questionar qual seu conceito. Para tanto, recorre-se às concepções de Mowday, Porter e Steers (1979 apud SOLDI, 2006) os quais destacam que comprometimento não se refere apenas à lealdade do indivíduo para com seu local de trabalho, mas vai muito além. Assim, definem:

Comprometimento é uma relação forte entre um indivíduo identificado e envolvido em uma organização em particular, e pode ser caracterizado por pelo menos três fatores: (1) tendência a manifestar um esforço considerável em benefício da organização; (2) uma forte crença e aceitação dos objetivos e valores da organização; e (3) manifestação de um forte desejo de se manter como membro da organização (MOWDAY; PORTER; STEERS, 1979 apud SOLDI, 2006, p. 25).

Os indivíduos com alto nível de comprometimento tendem a "abraçar" os valores e objetivos da empresa, exercendo maior esforço na execução destes. Além disso, são ativos e bem dispostos, estão sempre prontos para contribuir ao máximo com a organização.

Tais aspectos foram vistos em matéria teórica. Na próxima etapa, pretende-se mostrar a prática desses fundamentos por meio dos resultados da pesquisa de campo. 


\section{COMPROMETIMENTO COM A EMPRESA: ANÁLISE A PARTIR DA PERCEPÇÃO DOS GESTORES}

Os dados, além de descritos, também estão expostos em gráficos. A escala aplicada aos gestores teve o objetivo de analisar o comprometimento, a satisfação e a identificação dos gestores com a empresa. Cada item da escala recebeu uma avaliação dos participantes que vai desde "discordo totalmente" a "concordo totalmente".

Ao longo desse estudo, viram-se conceitos sobre o tema proposto, além de um breve "passeio" sobre as bases do comprometimento. Nessa etapa, serão explicitados os resultados do estudo. As questões propostas aos gestores da Advance Comunicação estão interligadas ao objetivo geral da pesquisa, ou seja, descrever o vínculo organizacional do indivíduo com a instituição, em síntese, seu comprometimento.

\subsection{IDENTIFICAÇÃO COM A EMPRESA}

$\mathrm{O}$ primeiro grupo de questões analisado visa, especificamente, à identificação dos gestores frente à instituição, bem como identificar os elos existentes. $\mathrm{O}$ indivíduo, ao fazer parte de uma organização, pode ou não fazer ligações com ela. Regato (2008, p. 93, grifo nosso) aponta algumas pontes que podem realizar essas ligações:

A ponte da identificação - Estabelecida quando o indivíduo se identifica com os valores, a cultura ou o caráter da empresa $[\ldots]$.

A ponte da motivação - $O$ indivíduo se sente bem no ambiente da empresa, encontrando espaço e situações em que se percebe considerado como ser humano.

A ponte da dedicação - Ocorre quando os dois fatores acima estão presentes no dia a dia do indivíduo.

A ponte da segurança - Ocorre quando os colaboradores percebem o salário e os benefícios que a empresa oferece como meios dos quais depende o seu sustento.
No presente estudo, alguns desses aspectos podem ser claramente encontrados, conforme demonstra a seguir o Gráfico 1. Vale ressaltar que os valores do gráfico representam o percentual de pessoas que acreditam que determinado fator (ou ponte) ocorre na empresa.

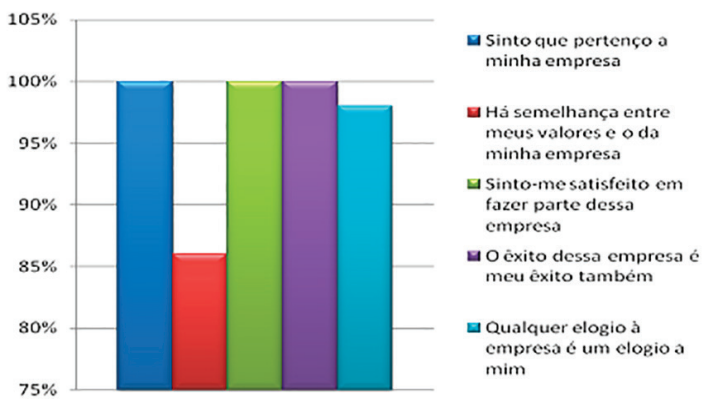

Gráfico 1 - Identificação com a empresa Fonte: pesquisa direta (2015).

A ponte da identificação logo é reconhecida por unanimidade nos seguintes fatores: sinto que pertenço a minha empresa, sinto-me satisfeito em fazer parte dessa empresa e o êxito dessa empresa é meu êxito também. Ao identificar-se com a empresa, o indivíduo se vê como cumpridor de uma missão pessoal, daí porque o sucesso da empresa é também o êxito do gestor. Assim, à medida que a empresa é elogiada, sente-se elogiado quem está à frente. Concordam com esse ponto $98 \%$ dos gestores.

Pode-se constatar que há um alto nível de afinidade entre os gestores e a empresa. Isso também é expresso quando $85 \%$ dos integrantes concordam que há semelhanças entre seus valores e os valores da organização. Robbins (2005, p. 54) afirma que "os valores representam convicções básicas de que um modo específico de conduta ou de condição de existência é individualmente ou socialmente preferível". De maneira geral, "são relativamente estáveis ou duradouros." (ROBBINS, 2005, p. 54). São, portanto, pessoas que "vestem a camisa" da empresa.

A percepção da reciprocidade também esteve presente em alguns itens. Segundo Siqueira (2003 apud ZANELLI; BORGES-ANDRADE; BASTOS, 2004, p. 312), essa percep- 
ção se trata de "um conjunto de crenças acerca do estilo retributivo adotado pela organização perante contribuições ofertadas por seus empregados." O próximo gráfico destaca três itens que se encaixam nesse aspecto:

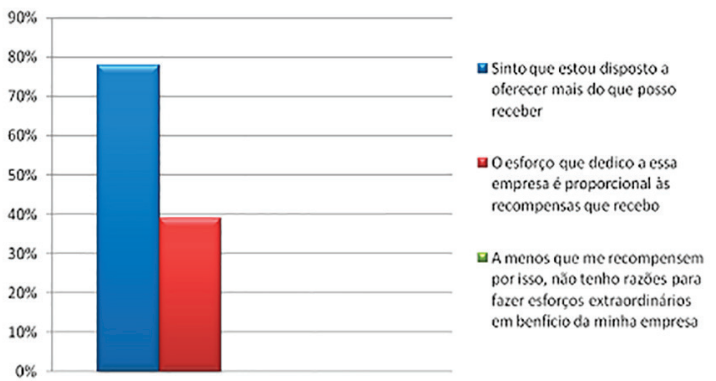

Gráfico 2 - Percepção da reciprocidade

Fonte: pesquisa direta (2015).

O indivíduo desenvolve expectativas sobre possíveis retribuições em relação a determinados atos de trabalho. Pode-se perceber uma redução no percentual quando se trata desse aspecto. Do total, 78\% afirmam oferecer mais do que podem receber. Apenas 39\% concordam que há reciprocidade no tocante ao esforço realizado. Ainda, assim, estão dispostos a aumentar esforços em benefício da empresa, visto que o último item não recebeu nenhum voto dos gestores.

Identifica-se a base afetiva do comprometimento muito forte nessa instituição, sobretudo, pelo sentimento de pertença e da relação de valores, vistos no gráfico 1 .

A base afetiva reflete o entendimento de que o indivíduo desenvolve uma forte identificação com a empresa e "nutre por ela sentimentos positivos ou negativos." (SIQUEIRA; GOMIDE JUNIOR, 2004, p. 314).

\subsection{COMPROMETIMENTO, SATISFA- ÇÃO}

O termo comprometimento associado a essa pesquisa se refere ao relacionamento da pessoa com a organização em que trabalha retomando o conceito de comprometimento trabalhado nesse estudo: "relação forte entre um indivíduo identificado e envolvido em uma organização em particular." (MOWDAY; PORTER; STE-
ERS, 1979 apud SOLDI, 2006); logo se percebe que se comprometer significa estar vinculado à empresa, ou seja, ter desejo de permanecer no exercício de determinada ação. É, também, o processo pelo qual os trabalhadores expressam sua preocupação com o sucesso da organização.

Nesse sentido, o gráfico a seguir mostra os resultados dessa etapa da pesquisa:

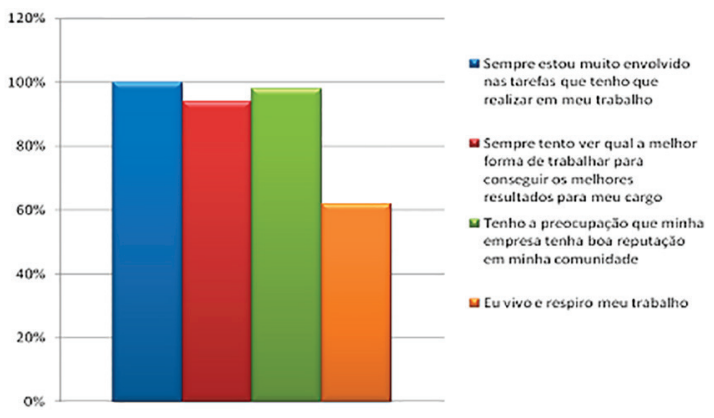

Gráfico 3 - Comprometimento com a empresa Fonte: pesquisa direta (2015).

Todos os gestores afirmam estar totalmente envolvidos com a empresa, ou seja, mediante a citação, pode-se concluir que estes estão comprometidos com a instituição e estão prontos a se esforçarem ao máximo pelo sucesso desta. Assim, concordam $94 \%$ dos participantes, que estão sempre em busca de novas estratégias por melhores resultados.

O comprometimento dos gestores vai além. Observa-se que $98 \%$ estão preocupados com que a empresa tenha uma boa imagem em seu entorno. Além disso, $62 \%$ consideram "que vivem e respiram" o próprio trabalho. Bastos (2000) identifica quatro padrões de comprometimento, a saber:

Duplo compromisso: níveis altos e semelhantes de comprometimento organizacional e com a organização.

Duplo descompromisso: baixos comprometimentos com a organização e com a profissão.

Unilateral com a organização: comprometimento mais alto com a organização do que com a profissão.

Unilateral com a profissão: comprometimento mais alto com a profissão do que com a organização (BASTOS, 
2000 apud SIQUEIRA; GOMIDE JUNIOR, 2004, p. 315, grifo do autor).

Nesse caso, pode-se denominar esse comprometimento de "duplo compromisso", visto que revela a preocupação dos gestores com a organização e com o cargo que ocupam.

Para falar da satisfação dos gestores com a instituição, destacou-se apenas um item da escala, que não consta no gráfico: o desejo continuar trabalhando na empresa. Quase que o total $(98 \%)$ dos gestores elegeu a opção "concordo totalmente". Com isso, pode-se estabelecer a relação comprometimento-satisfação. A satisfação revela um estado de prazer, apesar de não se adquirir de forma gratuita. É necessário esforço e dedicação, perceptível na análise feita sobre a opinião desses gestores.

\subsection{DESEMPENHO}

\subsubsection{Características organizacionais e desempenho}

Segundo O'Reilly e Pfeffer (2001), nos últimos anos, as empresas têm despendido uma grande quantidade de esforços na busca e na retenção de pessoas melhor qualificadas e que estejam propensas a serem comprometidas.

Entre as características organizacionais que atuam como antecedentes ao comprometimento, as características dos sistemas de gestão de pessoas são um componente de extrema importância. Meyer e Allen (1997) indicam a necessidade de se examinar os impactos dos sistemas de recursos humanos no comprometimento dos empregados. Para os autores, deve-se conhecer como se forma o comprometimento para melhor se desenhar o sistema de recursos humanos de uma empresa. Nesse sentido, Bastos (1994) relatou que três grandes conjuntos de práticas organizacionais estimulam o comprometimento: produtos gerados pelos processos de seleção; treinamento e qualificação; política de reconhecimento e recompensas. De modo semelhante, Bandeira, Marques e Veiga (1999) afirmaram que determinadas práticas de $\mathrm{RH}$, tais como políticas de treinamento e carreira, estimulam o comprometimento normativo e o afetivo.

Becker, Huselid e Ulrich (2001, p. 32) apresentam resultados mostrando que empresas com sistemas de trabalho de alto desempenho possuem receitas por empregados $290 \%$ maiores do que as empresas com sistemas de baixo desempenho.

Qual a relação desses fatores com o desempenho? Um trabalhador feliz é um trabalhador produtivo? A relação satisfação-desempenho é mais comum em níveis hierárquicos mais altos, como é o caso dessa pesquisa.

Para responder essa questão, a qual se apoia, também, em um único item que, apesar de ser solo, é bem direto: estar satisfeito com o trabalho eleva o desempenho profissional? A resposta veio por unanimidade, ou seja, 100\% dos gestores afirmaram que "sim".

É crescente a associação feita atualmente entre a o nível de satisfação dos trabalhadores dentro das empresas e os resultados apresentados por elas. Quanto mais satisfeito é o trabalhador, maior torna-se o seu desempenho.

\section{CONSIDERAÇÕES FINAIS}

Este trabalho pretendeu estabelecer a relação comprometimento-satisfação-desempenho. Quanto ao primeiro objetivo específico que é compreender, à luz da bibliografia, o que é comprometimento organizacional, apoia-se no conceito de Mowday, Porter e Steers (1979 apud SOLDI, 2006, p. 25) "comprometimento é uma relação forte entre um indivíduo identificado e envolvido em uma organização em particular."

Com relação aos objetivos seguintes: verificar o grau de comprometimento dos gestores da Advance Comunicação e o quanto estes se identificam com a empresa, foi possível constatar, mediante a escala desenvolvida por Quijano (NAVARRO et al., 2008), que os gestores estão satisfeitos com seu trabalho, se esforçam em prol do sucesso da empresa, ou seja, possuem um alto nível de comprometimento afetivo com a organização, o que se verifica pelo sentimento de pertença. 
Verificou-se que criar uma identidade com a empresa é imprescindível para se esforçar em ter um bom desempenho. Estar satisfeito também tem relação direta, uma vez que esse sentimento desencadeia outros: prazer em fazer parte da instituição, vontade de participar mais e contribuir.

Pode-se inferir com esses resultados que a empresa Advance Comunicação, de um modo geral, é gerenciada por pessoas comprometidas e satisfeitas com o que fazem. Também, é possível considerar que a instituição tem investido em gestão de pessoas, caso contrário os resultados obtidos seriam contrários, não haveria satisfação por parte dos funcionários.

Pode-se observar que diante da impossibilidade de se considerar o comprometimento apenas como atitude. A quantidade de indicadores comportamentais fortalece a recomendação de Mowday, Porter e Steers (1982) de que a vertente comportamental precisa ser incrementada e de que os estudos baseados apenas em medidas atitudinais são insuficientes. Comportamentos e disposições atitudinais são partes integrantes e integradas do conceito de comprometimento no cotidiano dos servidores estudados.

Este trabalho não tem a intenção de esgotar o assunto (nem seria possível) por se tratar de uma temática ampla, embora carente de estudos no âmbito local. Essa foi uma limitação encontrada durante as pesquisas: a maior parte da produção direta era de autores estrangeiros. Que esta pesquisa seja uma contribuição e possa incorporar o rol de estudos sobre comprometimento, gerando, assim, novas inquietações para futuros estudos, visto que nem tudo pôde ser abordado, por exemplo: qual o papel do gestor no comprometimento dos colaboradores? Dessa forma, há muito que ser estudado; esta é apenas uma pequena janela que foi fechada.

\section{ADMINISTRATIVE COMMITMENT IN ADVANCE COMMUNICATION: A STUDY ON THE PERCEPTION OF MANAGERS}

\section{ABSTRACT}

This paper presents a study on administrative commitment in Advance Communication in the perception of managers. The objective of this study is to verify the degree of commitment of the managers of Advance Communication and how they identify with the company. In the research carried out, we question how the commitment of the managers of Advance relates with work satisfaction, quality of life at work and how that reflects in performance. To carry out the research, a quantitative approach was carried out. A (NAVARRO et al., 2008) scale was used for data collection and data analysis was based on the categories: commitment, identification with the company, satisfaction and performance. As a result it was verified that there is a high level of affinity between the managers and the company, which reveals the affective basis of the strong commitment in this institution. In addition, managers attest that the more satisfied an employee is, the greater their performance. It is considered, therefore, that the aforementioned organization, in general, is managed by committed people, who are satisfied with what they do. Also, it is possible to consider that the institution has invested in people management, otherwise there would be no satisfaction from the employees.

Keywords: Commitment. Job Satisfaction. People Management. 


\section{COMPROMETIMIENTO ADMINISTRATIVO EN ADVANCE COMUNICACIÓN: UN ESTUDIO DESDE LA PERCEPCIÓN DE LOS GESTORES}

\section{RESUMEN}

Este artículo presenta un estudio sobre el comprometimiento administrativo en Advance Comunicación a la luz de la percepción de los gestores. El objetivo de este estudio es verificar el grado de comprometimiento de los gestores de Advance Comunicación y cuanto ellos se identifican con la empresa. En la investigación realizada, se cuestiona como se establece la relación entre el comprometimiento de los gestores de Advance con la satisfacción en el trabajo, la cualidad de vida en el trabajo y cuáles son los reflejos en el desempeño. Para la concretización de la investigación, se realizó un estudio con abordaje cuantitativo. Se utilizó para colectar los datos una escala (NAVARRO et al., 2008), y el análisis de los datos ocurrió en función de las categorías: comprometimiento, identificación con la empresa, satisfacción y desempeño. Como resultado, se verificó que hay un alto nivel de afinidad entre los gestores y la empresa, lo que revela la base afectiva del comprometimiento fuerte en esa institución. Además, los gestores atestan que cuanto más satisfecho es el trabajador, mejor es su desempeño. Se considera, así, que la organización investigada, de un modo general, es dirigida por personas comprometidas y satisfechas con lo que hacen. También es posible considerar que la institución ha investido en la gestión de personas, caso contrario no habría satisfacción por parte de los funcionarios.

Palabras-clave: Comprometimiento. Satisfacción en el Trabajo. Gestión de Personas.

\section{L'ENGAGEMENT ADMINISTRATIF CHEZ ADVANCE COMMUNICATION: UNE ETUDE DEPUIS LA PERCEPTION DES GERANTS}

\section{RESUME}

Cet article présente une étude sur l'engagement administratif chez Advance Communication à la lumière de la perception des gérants. L'objectif de cette étude est de vérifier la mesure d'engagement des gérants de Advance Communication et à quel point ils s'identifient avec l'entreprise. Dans la recherche réalisée, nous nous sommes interrogés sur comment s'établit la relation entre l'engagement des gérants de Advance avec la satisfaction au travail, la qualité de la vie au travail et quels sont les refles sur les résultants. Pour concrétiser la recherche, nous avons réaliser une étude d'abordage quantitatif. Nous avons utilisé une échelle (NAVARRO et al., 2008) pour collecter les données, qui ont été analysées selon les catégories : engagement, identification avec l'entreprise, satisfaction et résultats. Comme produit nous avons vérifié qu'il y a un haut niveau d'affinité entre les gérants et l'entreprise, ce qui revelle la base affective du fort engagement dans cette institution. De plus, les gérants attestent que le plus satisfait un employé, le plus il présente des bons résultat. Nous considérons, ainsi, que l'organisations sous analyse est dirigée par des personnes engagées et satisfaite avec ce qu'elles font. Il est aussi possible de considérer que l'institution investit en gestion de personnes, sinon il n'y aurait pas de satisfaction de la partie des employés.

Mots-clés: Engagement. Satisfaction au Travail. Gestion de Personnes.

1 De acordo com Souza (1978), o clima organizacional é um fenômeno resultante da interação dos elementos da cultura, como preceitos, caráter e tecnologia. Decorre do peso dos efeitos de cada um desses elementos culturais, valores, políticas, tradições, estilos gerenciais, comportamentos, expressões dos indivíduos envolvidos no processo e também resultante do conjunto de instrumentos, conhecimentos e processos operacionais da organização. 


\section{REFERÊNCIAS}

AMARO, Ana; PÓVOA, Andreia; MACEDO, Lúcia. A arte de fazer questionários. Porto: Faculdade de Ciências da Universidade de Porto, 2005.

BANDEIRA, M. L.; MARQUES, A. L.; VEIGA, R. T. As dimensões múltiplas do comprometimento organizacional: um estudo na ECT/ MG. In: ENCONTRO ANUAL DA ANPAD, 23., 1999, Foz do Iguaçu. Anais... Foz do Iguaçu: ANPAD, 1999.

BASTOS, A. V. B. Comprometimento organizacional: uma análise do conceito expresso por servidores universitários no cotidiano de trabalho. Revista Administração contemporânea, Curitiba, v. 1, n. 2, jul./ago. 1997.

Comprometimento organizacional:um balanço dos resultados e desafios que cercam essa tradição de pesquisa. Revista de Administração de Empresas, Curitiba, v. 33, p. 52-64, maio/jun. 1993.

O conceito de comprometimento: sua natureza e papel nas explicações do comportamento humano no trabalho. Organização e Sociedade, Salvador, v. 1, n. 2, p. 77-106, 1994.

Padrões de comprometimento com a profissão e com a organização: o impacto dos fatores pessoais e da natureza do trabalho. Revista de Administração (RAUSP), São Paulo, v. 35 , n. 4 , p. 48-60, out./dez. 2000.

BASTOS, Antônio Virgílio Bittencourt; ANDRADE, Jairo Eduardo Borges. Medidas de comprometimento no contexto de trabalho: um estudo preliminar de validade discriminante. Revista de Administração de Empresas, São Paulo v. 42, n. 2, p. 29-48, abr.jun. 1992.

BECKER, B. E.; HUSELID, M. A.; ULRICH, D. Gestão estratégica de pessoas com "scorecard": interligando pessoas, estratégia e performance. Rio de Janeiro: Campus, 2001.
BECKER, T. E. Foci and bases of commitment: are they distinctions worth making? Academy of Management Journal, v. 35, n. 1, p. 232244, 1992.

BRASIL. Ministério da Saúde. Resolução $n^{\circ}$ 466, de 12 de dezembro de 2012. Biblioteca Virtual em Sáude, 2012. Disponível em: < http://bvsms.saude.gov.br/bvs/saudelegis/ cns/2013/res0466_12_12_2012.html>. Acesso em: 5 abr. 2016.

FLEURY, A.; FLEURY, M. T. L. Estratégias empresariais e formação de competências: um quebra-cabeças caleidoscópico da indústria brasileira. Rio de Janeiro: Atlas, 2001.

HENTZ, Luiz A. S. Direito empresarial: doutrina - jurisprudência. 2. ed. Leme: Editora de Direito, 1998.

MEDEIROS, C. A. F. Comprometimento Organizacional: um estudo de suas relações com características organizacionais e desempenho nas empresas hoteleiras. 2003. $166 \mathrm{f}$. Tese (Doutorado em Administração), Universidade de São Paulo, São Paulo, 2003.

MEYER, J. P.; ALLEN, N. J. Comprometimento no local de trabalho: teoria, pesquisa e aplicação. California (EUA): Sage Publications, 1997.

MORIN, Stelle M. Os sentidos do trabalho. Tradução Ângelo Soares. Revista de Administração de Empresas, São Paulo, v. 41, n. 3, p. 8-19, jul./set. 2001.

MOWDAY, R. T.; PORTER, L. W.; STEERS, R. M. Employee-organization linkages: the psychology of commitment, absenteism, and turnover. New York: Academic Press, 1982.

NAVARRO, José et al. Propuesta de un modelo y validación empírica. Revista de Psicologia Social, v. 23, n.2, p. 259-273, 2008. 
O'REILLY III, C.; PFEFFER, J. Talentos ocultos: como as melhores empresas obtêm resultados extraordinários com pessoas comuns. Rio de Janeiro: Campus, 2001.

REGATO, Cardoso Vilma. Psicologia nas organizações. Rio de Janeiro: Ltc, 2008.

REICHERS, A. E. Revisão e reconceitualização do comprometimento organizacional. Academia de Revisão Administrativa, v. 10, n. 3, p. 465-476, out. 1985 .

ROBBINS, Stephen P. Comportamento organizacional. Tradução Reynaldo Marcondes. São Paulo: Pearson Prentice Hall, 2005.

SAAD, Sheila Madrid. Profissionalização e gestão de pessoas. Revista Empresa Familiar, Santa Maria, v. 6, n. 1, p.71-89, jan./mar. 2005.

SIQUEIRA, M. M. M.; GOMIDE JÚNIOR, S. Vínculos do indivíduo com o trabalho e com a organização. In: ZANELLI, J. C.; BORGES-ANDRADE, J. E.; BASTOS, A. V. B. (Org.). Psicologia, organizações e trabalho no Brasil. Porto Alegre: Artmed, 2004. p. 357-379.

SOLDI, R. M. Comprometimento organizacional de trabalhadores terceirizados e efetivos: um estudo comparativo em uma empresa de telefonia. 2006. 133 f. Dissertação (Mestrado em Administração) - Universidade Federal de Santa Catarina, Santa Catarina, 2006.

SOUZA, Edela Lanzer Pereira de. Clima e cultura organizacionais: como se manifestam e como se manejam. Porto Alegre: Edgar Blücher, 1978.

TAMAYO, Álvaro. Impacto dos valores pessoais e organizacionais sobre o comprometimento organizacional. In: TAMAYO, Álvaro; PORTO, Juliana Barreiros (Org.). Valores e comportamento nas organizações. Rio de Janeiro: Petrópolis: Vozes, 2005. p. 160-185.
TEIXEIRA, Elizabeth. As três metodologias: acadêmica, da ciência e da pesquisa. 4. ed. Belém: UNAMA, 2001.

TEIXEIRA, M. G. Comprometimento organizacional: uma análise dos fatores individuais numa empresa de prestação de serviços. In: REUNIÃO ANUAL DA ASSOCIAÇÃO DE PROGRAMAS DE PÓS-GRADUAÇÃO EM ADMINISTRAÇÃO, 18., 1994, Curitiba. Anais... Florianópolis: ANPAD, 1994. v. 10. p. 268-286.

VASCONCELOS, A. F. Qualidade de vida no trabalho: origem, evolução e perspectivas. Caderno de Pesquisas em Administração, São Paulo, v. 8, n. 1, jan./mar. 2001.

WIENER, Y.Commitment in organizations: normative view. Academy of Management Review, United States, v. 7, p. 418-428, 1982.

YIN, Robert K. Estudo de caso: planejamento e métodos. 2. ed. Porto Alegre: Bookman. 2001 .

ZANELLI, J. C.; BORGES-ANDRADE, J. E.; BASTOS, A. V. B. (Org.). Psicologia, organizações e trabalho no Brasil. Porto Alegre: Artmed, 2004. 